\title{
Correlation between Flexural and Compressive Properties of Kenaf/Epoxy Composite filled with Mesoporous Silica
}

\author{
Chai Hua, T., Norkhairunnisa, M.
}

\begin{abstract}
This research investigates the relationship between flexural and compressive properties of kenaf/epoxy composite filled with mesoporous silica, through regression analysis. EpoxAmite ${ }^{\circledR} 100$ Epoxy and 103 Hardener were used as matrix, modified by constant volume of silicon, different percentage of mesoporous silica, and reinforced with constant volume of kenaf mat. Three pointer bend fixture and compression test were conducted and the data were used for regression analysis. Flexural test revealed that inclusion of 5 vol\% mesoporous silica and 3 vol\% silicon into $7.2 \mathrm{Vol} \% \mathrm{~K} / \mathrm{Ep}$ resulted in the highest flexural strength, while the highest flexural modulus is achieved at 3 vol\% SiaK/Ep. Compressive strength and compressive modulus are both the highest at 1vol\% SiaK/Ep-Si. Good correlations were established when kenaf is used as single independent variable to predict compressive modulus of the composites produced. On the other hand, poor correlation is obtained when silicon and mesoporous silica are used as the two independent variables in predicting flexural strength, flexural modulus, compressive strength and compressive modulus. When kenaf is included as the third independent variable (together with silicon and mesoporous silica) in predicting the four results, correlation is found to improve tremendously. However, all four multivariate regression relationships established between flexural and compressive data results in an average value ranging from 0.5 to 0.6 .
\end{abstract}

Index Terms: Compressive test, Flexural test, Natural fibre reinforced polymer, Regression analysis

\section{INTRODUCTION}

The expanding use of natural fibre in composite is due to its various advantages such as wide availability and biodegradability. Low density and high specific properties make natural fibre a good candidate as reinforcement in thermoplastic and thermoset polymer composites. The properties, composition, structures and features of natural fibre are suitable to be incorporated in polymer composites as either reinforcements or fillers [1], [2]. Due to this, the reinforcement of natural fibres into composite material has been conducted by many researches up to date [3]-[8]. Also, much attention is now centred to producing sustainable and renewable polymeric materials [9].

Revised Manuscript Received on July 05, 2019.

Chai Hua, T. ${ }^{1}$, Department of Aerospace Engineering, Faculty of Engineering, UPM, 43400 UPM Serdang, Selangor Darul Ehsan, Malaysia. Corresponding author.Email: peggytay_92@yahoo.com

Norkhairunnisa, M. Department of Aerospace Engineering, Faculty of Engineering, UPM, 43400 UPM Serdang, Selangor Darul Ehsan, Malaysia, \& High Center of Excellence (HiCoE), Institute of Tropical Forestry and Forest Products (INTROP), Universiti Putra Malaysia, 43400 UPM, Serdang, Selangor

Corresponding author. Email: norkhairunnisa@upm.edu.my
Despite the advantages, natural fibres have some major drawbacks that can affect the overall performance of composite produced. Its high degree of moisture absorption and poor dimensional stability issues can be solved through chemical treatment of natural fibre. Sources of chemical treatments include alkali, silane, acetylation, benzoylation, acrylation and acrylonitrile grafting, maleated coupling agents, permanganate, peroxide, isocyanate, stearic acid, sodium chlorite, triazine, fatty acid derivate (oleoyl chloride) and fungal [10]. Many researches on influence of treated natural fibres have been reported [11]-[20].

Hybridization of natural fibre and synthetic fibre are also extensively studied. Even though natural fibre may play an important role in producing biodegradable composites to resolve environmental issues, it has low mechanical properties compared to synthetic fibres such as glass. Thus, hybridization of natural fibres and synthetic fibres can make the composite produced relatively cheaper and easier to be used. [21] Recent works on using both glass fibre and natural fibre in composites have been reported [22], [23].

The performance of a composite can be further improved by incorporating fillers into the matrix. For example, the presence of cellulosic fillers improved the mechanical properties of composites compared to those containing non-fibrous fillers [24]. Nanotechnology has brought new opportunities to improve the mechanical and multifunctional properties of Fibre Reinforced Polymer (FRP). The incorporation of nanoscale fillers such as carbon nanotubes (CNT) and carbon nanofibers (CNF) modify the properties. of polymer matrix. [25] Due to this, various researches have been done on incorporation of nanoscale fillers into composites [26]-[30].

Even though a number of researches on Natural Fibre Reinforced Polymer (NFRP) filled with nanoparticles have been produced, not many papers are published on the mathematical equation relating the composite's materials and its flexural and compressive properties. A good mathematical model can contribute to significant economic benefits. This is because the model allows good estimation of composite's properties based on only several conducted experiments. The reduced number of experiments is cost effective since the amount of materials used is lesser [31]

\section{A. Regression Techniques}

Regression Techniques (RT) is a mathematical modelling of correlation between dependent 


\section{Correlation between Flexural and Compressive Properties of Kenaf/Epoxy Composite filled with Mesoporous Silica}

variables and dependent variables. In other words, it is the relationship between one or more measured variables with another variable that is related to the measured ones. Independent variable can also be called explanatory variable or influencing variable while dependent variable as the influenced one [32]. Regression models can be classified into linear and nonlinear regression. Linear regression models are very easy to be estimated, thus a great deal of applied work in econometrics are using them [33].

\section{MATERIALS AND METHODOLOGY}

\section{A. Materials}

The epoxy used is EpoxAmite $₫ 100$ with 103 slow hardener from Smooth-On. The mixture of epoxy and hardener takes one hour to cure under room temperature. The reinforcement of the composite is woven kenaf mat from Bangladesh, extracted from the bast fibre of kenaf plant. The fillers which are mesoporous silica and silicon were bought from Maerotech and Wacker respectively. The mesoporous silica is chemically stable white particle, often used as insulation material and fillers. Silicon used is of the type Genioperl ${ }^{\circledR}$ P52, a particulate polymer modifier in powder form, known to improve the impact strengths of thermoplastic and thermoset polymer systems at low temperatures.

\section{B. Methodology}

Both the fillers and epoxy are mixed in a styrofoam cup using homogenizer, with stirring speed of 3000rpm for a minute. Then the mixture is placed in a vacuum oven to remove bubbles. Presence of bubbles is known to degrade the performance of composite produced. Hardener is poured into the mixture, stirred using mechanical stirrer for 3-5 minutes at $300 \mathrm{rpm}$. Each laminated composite was produced by using vacuum infusion method, with only one layer of kenaf each. The specimens are left to cure in room temperature for a day and then post cured in oven for two hours at $80^{\circ} \mathrm{C}$. The compositions of samples produced are as shown in Table 1.

Table 1: Labelled name for 11 specimens produced with different material composition

\begin{tabular}{ccccc}
\hline Specimen & $\begin{array}{c}\text { Epoxy } \\
(\text { vol\%) }\end{array}$ & $\begin{array}{c}\text { Silicon } \\
(\text { vol\%) }\end{array}$ & $\begin{array}{c}\text { Kenaf } \\
(\text { vol\%) }\end{array}$ & $\begin{array}{c}\text { Mesoporous } \\
\text { Silica } \\
\text { (vol\%) }\end{array}$ \\
\hline Ep & 100 & 0 & 0 & 0 \\
Ep-Si & 97 & 3 & 0 & 0 \\
7.2\% K/Ep & 92.8 & 0 & 7.2 & 0 \\
$0.5 \%$ & 89.3 & 3 & 7.2 & 0.5 \\
SiaK/Ep-Si & & & & \\
$1.0 \%$ & 88.8 & 3 & 7.2 & 1.0 \\
SiaK/Ep-Si & & & & \\
3.0\% & 86.8 & 3 & 7.2 & 3 \\
SiaK/Ep-Si & & & & \\
5.0\% & 84.8 & 3 & 7.2 & 5 \\
SiaK/Ep-Si & & & 7.2 & 0.5 \\
$0.5 \%$ SiaK/Ep & 92.3 & 0 & 7.2 & 1.0 \\
$1.0 \%$ SiaK/Ep & 91.8 & 0 & 7.2 & 3 \\
3.0\% SiaK/Ep & 89.8 & 0 & 7.2 & 5 \\
$5.0 \%$ SiaK/Ep & 87.8 & 0 & & \\
\hline
\end{tabular}

\section{Characterization}

To ensure that epoxy is impregnated well into kenaf, Scanning Electron Microscope (SEM) was conducted on the samples produced. Specifically, the samples taken for observation are the samples after flexural test was conducted. The area where break off occurs will be used to observe the exposed inner structure. The samples are observed with magnification of $1 \mathrm{~mm}, 10 \mu \mathrm{m}, 50 \mu \mathrm{m}$ and $100 \mu \mathrm{m}$.

Flexural test was conducted using Instron 3365. Standard sample dimension of $125 \mathrm{~mm} \times 12.7 \mathrm{~mm} \times 3 \mathrm{~mm}$ were used, as stated in ASTM D790-02. The sample was placed on three pointer bend fixture and test was started and continued until there is sudden drop in compression loading, indicating that the specimen has failed structurally. Five samples were tested and the average values are tabulated. Two types of data obtain through flexural test, namely flexural strength and flexural modulus.

Compressive test was conducted using Instron 5900. Standard sample dimension used was $10 \mathrm{~mm}$ x $10 \mathrm{~mm}$ x $3 \mathrm{~mm}$, as required by ISO 604. Average data of 5 samples are taken and tabulated as well. There are two types of data obtained through compressive test, which are compressive strength and compressive modulus.

\section{RESULTS AND DISCUSSIONS}

\section{A. SEM Analysis}

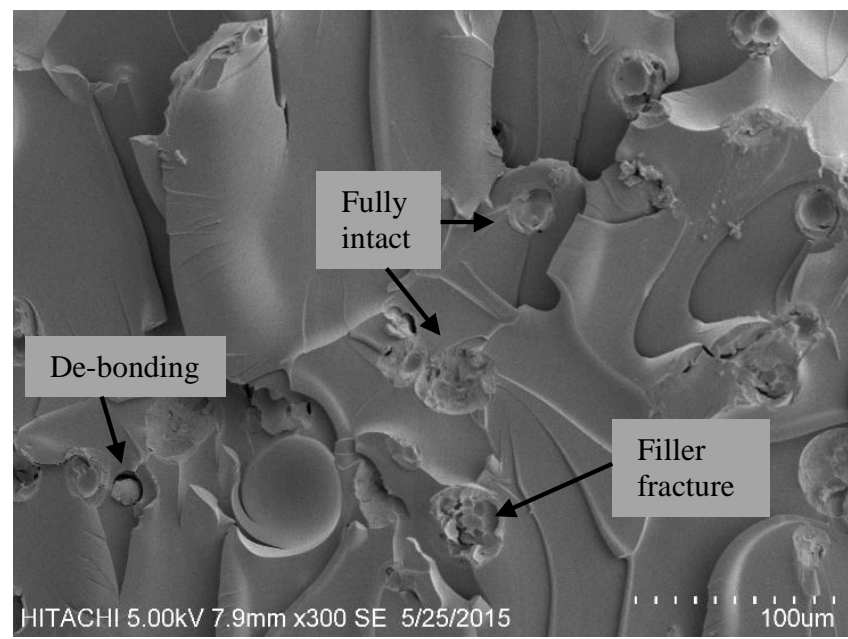

Fig. 1: Magnification of $100 \mu \mathrm{m} \mathrm{Ep-Si.}$

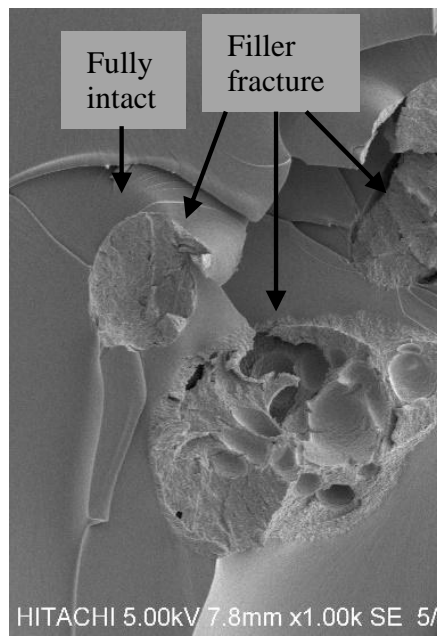

Fig. 2: Magnification of $50 \mu \mathrm{m}$ Ep-Si. 
Through SEM, the morphology of composite can be studied. Figure 1 and 2 shows the inner structure of Ep-Si hybrid. De-bonding, filler fracture and fully intact fillers can be seen in both figures. Fully intact fillers prove good interaction between silicon and epoxy. Filler fracture shows that silicon and epoxy bonded well and act as one composite and thus instead of debonding or separation between silicon and epoxy, breakage of silicon is observed. No pore is seen in fractured silicon, proving that it has excellent compressive property.

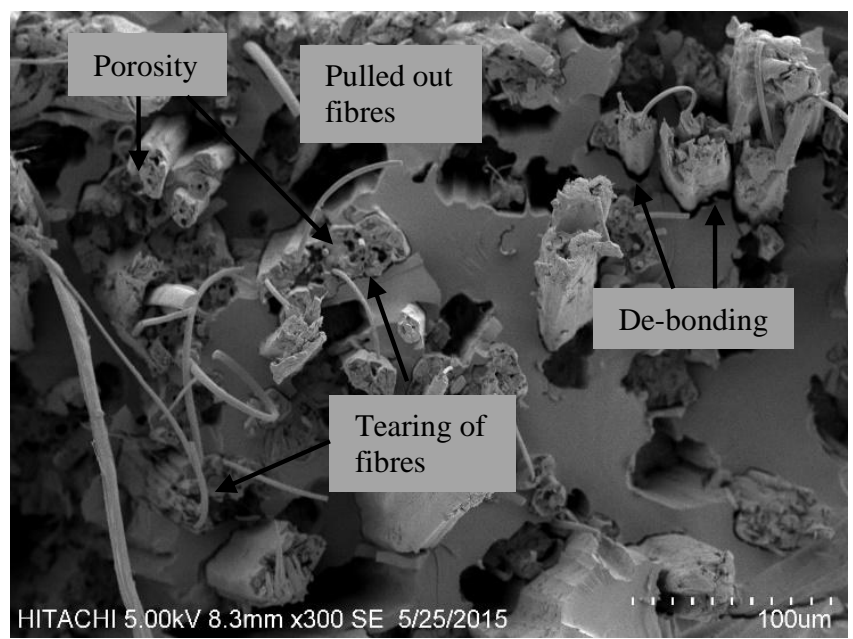

Fig. 3: Magnification of $100 \mu \mathrm{m} 7.2$ vol\% K/Ep

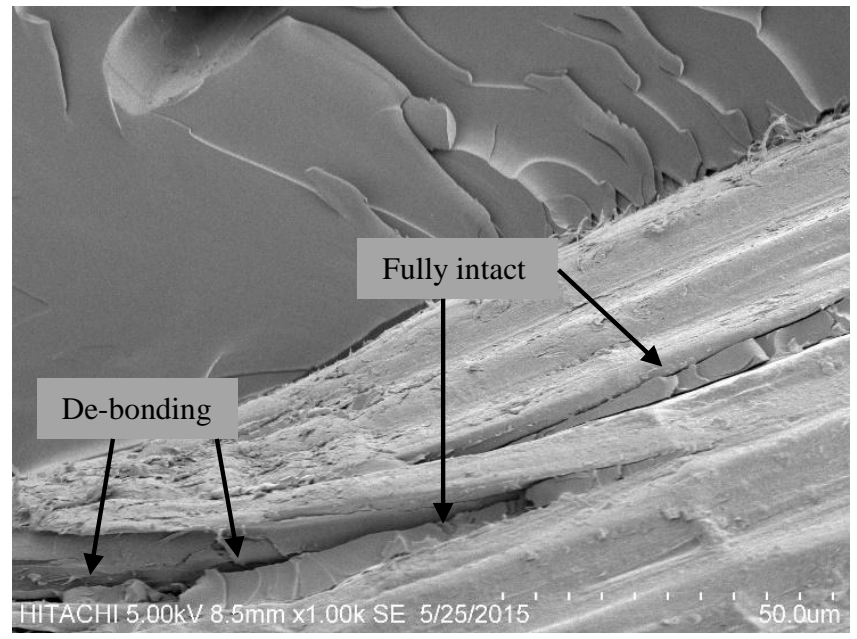

Fig. 4: Magnification of $50 \mu \mathrm{m} 7.2 \mathrm{vol} \% \mathrm{~K} / \mathrm{Ep}$

Figure 3 and Figure 4 shows the inner structure of $7.2 \mathrm{vol} \%$ $\mathrm{K} / \mathrm{Ep}$. Some kenaf are observed to be porous within and debondings are observed between kenaf and epoxy. Clear pull out and tearing of fibres are also seen. Porosity of fibre with no impregnation of epoxy and low interaction between fibre core and matrix leads to low mechanical performance of composite produced [34]. Clear pull out of fibres signifies lack of epoxy in kenaf and this contributes to low interfacial adhesion between them [35]. However, there are also some fully intact regions in the composite, proving that the performance of the composite might not be bad after all.

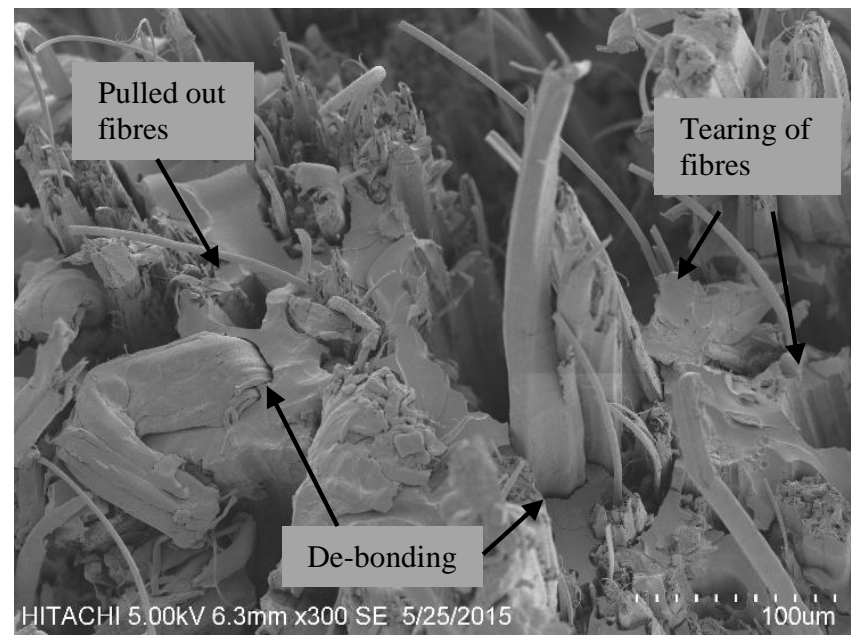

Fig. 5: Magnification of $100 \mu \mathrm{m} 0.5 \mathrm{vol} \% \mathrm{SiaK} / \mathrm{Ep}-\mathrm{Si}$.

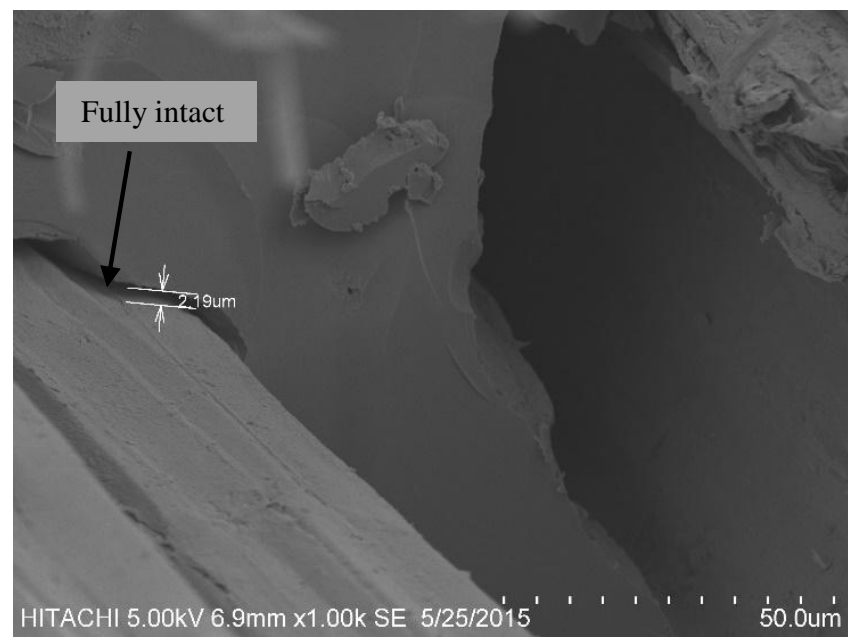

Fig. 6: Magnification of $50 \mu \mathrm{m} 0.5 \mathrm{vol} \% \mathrm{SiaK} / \mathrm{Ep}-\mathrm{Si}$.

Figure 5 and Figure 6 show less debonding compared to $7.2 \mathrm{vol} \% \mathrm{~K} / \mathrm{Ep}$ composite. Figure 6 reveals that the kenaf and epoxy bonded well with only $2.19 \mu \mathrm{m}$ gap. No clear gap indicates good bonding between fibre and resin, leading to well propagated stress in the composite, resulting in higher tensile strength and modulus [36]. Since SEM reveals that the fillers have good interaction with epoxy, regression analysis can be conducted to produce appropriate mathematical model to predict responses.

\section{B. Regression Analysis}

Tabulated data for flexural test and compressive test is as shown in Table 2. There are two types of regression model studied here. The first one is bivariate regression, where there is only one independent variable and one dependent variable. The second one is multivariate regression, where there are two or more independent variables and one dependent variable. Multivariate regression is better in predicting response compared to bivariate regression.

Table 2: Data obtained through flexural test and compressive test 


\begin{tabular}{|c|c|c|c|c|}
\hline $\begin{array}{c}\text { Composit } \\
\mathrm{e}\end{array}$ & $\begin{array}{c}\text { Flexura } \\
1 \\
\text { Strengt } \\
\text { h } \\
\text { (Mpa) }\end{array}$ & $\begin{array}{l}\text { Flexural } \\
\text { Modulu } \\
\text { s (Mpa) }\end{array}$ & $\begin{array}{c}\text { Compressi } \\
\text { ve Strength } \\
(\mathrm{Mpa})\end{array}$ & $\begin{array}{c}\text { Compressi } \\
\text { ve Modulus } \\
(\mathrm{Mpa})\end{array}$ \\
\hline Ep & 82.806 & $\begin{array}{c}2564.86 \\
4\end{array}$ & 1574.046 & 11573.15 \\
\hline Ep-Si & 51.026 & 2416.43 & 2448.544 & 9171.838 \\
\hline $\begin{array}{l}7.2 \% \\
\text { K/Ep }\end{array}$ & 21.982 & $\begin{array}{c}1415.28 \\
6\end{array}$ & 266.418 & 5612.078 \\
\hline $\begin{array}{c}0.5 \% \\
\text { SiaK/Ep- } \\
\text { Si }\end{array}$ & 19.318 & 543.422 & 560.826 & 6914.906 \\
\hline $\begin{array}{c}1.0 \% \\
\text { SiaK/Ep- } \\
\text { Si }\end{array}$ & 18.656 & 722.922 & 736.9687 & 7533.6 \\
\hline $\begin{array}{c}3.0 \% \\
\text { SiaK/Ep- } \\
\text { Si }\end{array}$ & 15.682 & 628.462 & 335.228 & 6406.332 \\
\hline $\begin{array}{c}5.0 \% \\
\text { SiaK/Ep- } \\
\text { Si }\end{array}$ & 32.808 & $\begin{array}{c}1092.94 \\
4\end{array}$ & 366.732 & 4397.838 \\
\hline $\begin{array}{c}0.5 \% \\
\text { SiaK/Ep }\end{array}$ & 18.02 & 661.98 & 35.736 & 4261.186 \\
\hline $\begin{array}{c}1.0 \% \\
\text { SiaK/Ep }\end{array}$ & 11.782 & 418.08 & 535.606 & 5065.18 \\
\hline $\begin{array}{c}3.0 \% \\
\text { SiaK/Ep }\end{array}$ & 31.34 & 1569.48 & 444.714 & 5064.982 \\
\hline $\begin{array}{c}5.0 \% \\
\text { SiaK/Ep }\end{array}$ & 35.14 & 982.998 & 113.516 & 4201.548 \\
\hline
\end{tabular}

\section{Bivariate Regression}

Bivariate Regressions are conducted to find the relationship between silicon and compressive modulus, kenaf and compressive modulus, and mesoporous silica and compressive modulus. The three correlations are compared and studied to check which filler has the highest significant effect on compressive modulus of composite produced.

Table 3: $\mathrm{R}$ squared value and equation obtained through bivariate regression

\begin{tabular}{l|c|c}
\hline $\begin{array}{l}\text { Independent } \\
\text { Variable }\end{array}$ & $\begin{array}{c}\mathrm{R} \\
\text { Squared }\end{array}$ & Equation \\
\hline Silicon & 0.0432 & $\mathrm{y}=307.29 \mathrm{x}+5963$ \\
Kenaf & 0.7263 & $\mathrm{y}=-677.39 \mathrm{x}+10372$ \\
Mesoporous & 0.3534 & $\mathrm{y}=157.47 \mathrm{x} 2-1451.9 \mathrm{x}+$ \\
Silica & & 7880.7 \\
\hline
\end{tabular}

The value of $\mathrm{R}$ squared, also known as Coefficient of Determination, is a statistic that explains the amount of variance for relationship between variables. The higher the value of $\mathrm{R}$ squared, the more useful the mathematical model. $\mathrm{R}$ squared is a value between the range of 0 and 1 . From the Table 3 above, it can be seen that the relationship between kenaf and compressive modulus yields the highest $\mathrm{R}$ squared, followed by mesoporous silica and silicon. This shows that kenaf has the strongest relationship with the compressive modulus of composite. In other words, kenaf gives more significant effect on the composite's compressive modulus.

\section{Multivariate Regression}

Interaction between two or more variables and compressive modulus were obtained and $\mathrm{R}$ squared data are tabulated. From the Table 4 below, it can be seen that using three variables in predicting value of compressive modulus gives the highest $\mathrm{R}$ squared value. Silicon and mesoporous silica however, are not good indicators in predicting compressive value.

Table 4: R squared value obtained for compressive modulus

\begin{tabular}{lc}
\multicolumn{1}{c}{ Independent Variable } & R Squared \\
\hline \multicolumn{1}{c}{ Silicon and Kenaf } & 0.7560 \\
Kenaf and Mesoporous Silica & 0.7740 \\
Silicon and Mesoporous- Silica & 0.3924 \\
Silicon, Kenaf and & 0.8132 \\
Mesoporous Silica &
\end{tabular}

Interaction between two or more variables and compressive strength were obtained and $\mathrm{R}$ squared data are tabulated. From the Table 5 below, relatively the R squared obtained is high for each interaction, except for silicon and mesoporous silica. Similar as the Table 4, using three variables gives the highest $\mathrm{R}$ squared, indicating that the more the independent variables, better prediction of response can be made.

Table 5: R squared value obtained for compressive strength

\begin{tabular}{cc}
\hline Independent Variable & R Squared \\
\hline Silicon and Kenaf & 0.9107 \\
Kenaf and Mesoporous Silica & 0.8540 \\
Silicon and Mesoporous -Silica & 0.3258 \\
Silicon, Kenaf and & 0.9203 \\
Mesoporous Silica & \\
\hline
\end{tabular}

Interaction between two or more variables and flexural modulus were obtained and $\mathrm{R}$ squared data are tabulated. The same trend of result can be observed in the Table 5 and Table 6.

Table 6: R squared value obtained for flexural modulus

\begin{tabular}{cc}
\hline Independent Variable & R Squared \\
\hline Silicon and Kenaf & 0.7932 \\
Kenaf and Mesoporous Silica & 0.7826 \\
Silicon and Mesoporous Silica & 0.0811 \\
Silicon, Kenaf and & 0.8178 \\
Mesoporous Silica & \\
\hline
\end{tabular}

Interaction between two or more variables and flexural strength were obtained and R squared data are tabulated. The Table 7 below has the same trend as the Table 4.

Table 7: R squared value obtained for flexural strength

\begin{tabular}{cc}
\hline Independent Variable & R Squared \\
\hline Silicon and Kenaf & 0.7876 \\
Kenaf and Mesoporous Silica & 0.8255 \\
Silicon and Mesoporous Silica & 0.0387 \\
Silicon, Kenaf and & 0.8752 \\
Mesoporous Silica & \\
\hline
\end{tabular}

Comparing Table 4, Table 5, Table 6 and Table 7, it can be seen that the highest and lowest $\mathrm{R}$ squared are achieved by the same variables' interaction, where the highest is accounted for using silicon, kenaf and mesoporous silica as independent variables while the lowest is for using silicon and mesoporous silica as independent variables. This shows that using both 
powdered fillers as independent variables does not give good interaction with the mechanical properties results above. The prediction model using three independent variables is more reliable than those with one and two independent variables.

Since better relationship is obtained when two and more independent are used, the data below are tabulated using multivariate regression.

Table 8: R squared value between flexural and compressive data

\begin{tabular}{ccc}
\hline $\begin{array}{c}\text { Independent Variable } \\
(\mathrm{s})\end{array}$ & Dependent Variable & R Squared \\
\hline $\begin{array}{c}\text { Flexural Strength and } \\
\text { Flexural Modulus }\end{array}$ & $\begin{array}{c}\text { Compressive Strength } \\
\text { Flexural Strength and } \\
\text { Flexural Modulus } \\
\text { Compressive }\end{array}$ & $\begin{array}{c}\text { Compressive } \\
\text { Modulus }\end{array}$ \\
$\begin{array}{c}\text { Strength and } \\
\text { Compressive }\end{array}$ & Flexural Strength & 0.5447 \\
Modulus & & \\
Compressive & Flexural Modulus & 0.5557 \\
Strength and & & \\
Compressive & & \\
Modulus & & \\
\hline
\end{tabular}

It can be seen from Table 8 that all four $\mathrm{R}$ squared values obtained do not vary much. All the values obtained are rather average, neither good nor bad for prediction on the dependent variable. It can be concluded that compressive and flexural properties do not have strong interaction.

\section{CONCLUSIONS}

Regression analysis was conducted based on SEM images which displays good interaction between fillers and epoxy. Bivariate regression analysis reveals that the presence of kenaf gives the most significant effect on compressive modulus of composite. On the other hand, multivariate regression analysis shows that the interaction between three variables (silicon, kenaf and mesoporous silica) on compressive strength, compressive modulus, flexural strength and flexural modulus resulted in the highest $\mathrm{R}$ squared value, indicating that better properties prediction can be made. This result correlates with SEM images shown in Figure 5 and Figure 6 which displays less area of debonding within composite filled with silicon, kenaf and mesoporous silica. Compressive and flexural properties however, do not have strong correlation and possess $\mathrm{R}$ squared value of only slightly above medium.

\section{ACKNOWLEDGMENT}

The authors thank the Universiti Putra Malaysia (UPM), particularly the Department of Aerospace Engineering and Department of Mechanical Engineering for the infrastructures lend, enabling the project to be completed. Not to forget, supervisor of research project, Dr Norkhairunnisa for invaluable guidance and funding throughout the research project.

\section{REFERENCES}

1. M. S. Salit, "Chapter 2 Tropical Natural Fibres and Their Properties," in Tropical Natural Fibre Composites, Singapore, Springer Singapore, 2014, pp. 15-38.

2. K.-Y. Lee, K. C. Ho, K. Schlufter, J. M. Hodgkinson and A. Bismarck, "Bacterial Cellulose as the Binder for Natural Fibre Preforms to Produce Green Nanocomposites," ECCM15-15th European Conference on Composite Materials, 2012, pp. 24-28.

3. B. F. Yousif, A. Shalwan, C. W. Chin and K. C. Ming. (2012) Flexural Properties of Treated and Untreated Kenaf/Epoxy Composites. Materials and Design. vol. 40, pp. 378-385.

4. O. Faruk, A. K. Bledzki, H.-P. Fink and M. Sain. (2012). Biocomposites Reinforced with Natural Fibres 2000-2020. Progress in Polymer Science. vol. 37, p. 155201596.

5. K.-Y. Lee, Y. Aitomäki, L. A. Berglund, K. Oksman and A. Bismarck. (2014). On the Use of Nanocellulose As Reinforced In Polymer Matrix Composites. Composites Science and Technology. vol. 105 , pp. 15-27.

6. L. Mohammed , M. N. Ansari, G. Pua, M. Jawaid and M. Saiful Islam. (2015). A Review on Natural Fiber Reinforced Polymer Composite and Its Applications. International Journal of Polymer Science. vol. 2015, pp. 1-15.

7. C. Lee, M. S. Salit and M. Hassan. (2014). A Review of the Flammability Factors of Kenaf and Allied Fibre Reinforced Polymer Composites. Advances in Materials Sciences and Engineering. vol. 2014, 2014, pp. 1-8.

8. A. S. Singha and V. K. Thakur. (2008). Mechanical Properties of Natural Fibre Reinforced Polymer Composites. Indian Academy of Sciences. vol. 31, no. Bulletin of Material Science. pp. 791-799.

9. A. J. Ragauskas, C. K. Williams, H. D. Brian, G. Britovsek, J. Cairney, C. A. Eckert, W. J. Frederick Jr., J. P. Hallett, D. J. Leak, C. L. Liotta, J. R. Mielenz, R. Murphy, R. Templer and T. Tschapliski, "The Path Forward for Biofuels and Biomaterials," Science, vol. 311, 2006, pp. 484-489.

10. M. M. Kabir, H. Wang, K. T. Lau and F. Cardona,. (2011). Chemical Treatments on Plant-Based Natural Fibre Reinforced Polymer Composites: An Overview. Composites: Part B. pp. 2883-2892.

11. K.-S. Kim and S.-J. Park. (2010). Influence of Surface Treatment of Multi-walled Carbon Nanotubes on Interfacial Interaction of Nanocomposites. Carbon Letters, vol. 11, no. 2, pp. 102-106.

12. M. Rokbi, H. Osmani, A. Imad and N. Benseddiq. (2011). Effect of Chemical Treatment on Flexure Properties of Natural Fiber-Reinforced Polyester Composite. Procedia Engineering. vol. 10, pp. 2092-2097.

13. N. I. Mbada, O. Aponbiede, T. Ause and A. Alabi. (2016). Effects of Mercerization Treatment on Kenaf Fibre. International Journal of Materials Engineering. vol. 6, no. 1, pp. 8-14

14. V. Vinay (2013). Study on Mechanical Behaviour of Surface Treated Coir Fiber Reinforced Polymer Matrix Composites," National Institute of Technology, Rourkela.

15. M. M. Owen. (2014). The Effects of Alkali Treatment on the Mechanical Properties of Jute Fabric Reinforced Epoxy Composites. International Journal of Fiber and Textile Research. vol. 4, no. 2, pp. 32-40.

16. S. Milan, T. Christopher, J. T. Winowlin Jappes, I. Siva and R. Jayan Keasav Vennih (2015). Investigation on Mechanical Properties and Chemical Treatment of Sea Grass Fiber Reinforced Polymer Composites. Journal of Chemical and Pharmaceutical Sciences. no. 7, pp. 72-77.

17. N. Manap, A. Jumahat and N. Sapiai. (2015). Effect of Fibre Treatment on Longitudinal and Transverse Tensile Properties of Unidirectional Kenaf Composite. Jurnal Teknologi. vol. 76, no. 11, pp. 87-95.

18. J. W. Kaczmar, J. Pach and C. Burgstaller. (2011). The Chemically Treated Hemp Fibees to Reinforce Polymer. Polimery. vol. 2011, no. 56, pp. 817-822.

19. K. Joseph and S. Thomas (1996). Effect of Chemical Treatment on the Tensile Properties of Short Sisal Fibre-Reinforced Polyethylene Composites. Polymer. vol. 37, no. 23, pp. 5139-5149.

20. H. P. Abdul Khalil and H. Ismail. (2001). Effect of Acetylation and Coupling Agent Treatments Upon Biological Degradation of Plant Fibre Reinforced Polyester Composites. Polymer Testing. vol. 20, pp. 67-75.

21. M. Ramesh, K. Palanikumar and K. H. Reddy. (2013). Mechanical Property Evaluation of Sisal-Jute-Glass Fiber Reinforced Polyester Composites. Composites: Part B. pp. 1-9. 
22. N. Manap, A. Jumahat and A. Ludin. (2014). Tensile and Compressive Properties of Glass Reinforcement in Kenaf Reinforced Epoxy Composite. Advances in Environmental Biology. pp. 2673-2681.

23. M. M. Davoodi, S. M. Sapuan, A. Ali and D. Ahmad (2012). Effect of Strengthened Ribs in Hybrid Toughened Kenaf/Glass Epoxy Composite Bumper Beam. Life Science Journal. vol. 9, no. 1, pp. 285-289.

24. B. Wang, "Pre-Treatment of Flax Fibers For Use in Rotationally Molded Biocomposites," University of Saskatchewan, Saskatoon, 2004.

25. S. Tsantzalis, P. Karapappas, A. Vavoiliotis, P. Tsotra, V. Kostopoulos, T. Tanimoto and K. Friedrich. (2007). On the Improvement of Toughness of CFRPs with Resin Doped with CNF and PZT Particles. Composites Part A: Applied Science and Manufacturing. vol. 38, pp. 1159-1162.

26. M. G. Zaidi, S. Joshi, M. Kumar, D. Sharma, A. Kumar, S. Alam and P. Sah. (2013). Modifications of Mechanical, Thermal, and Electrical Characteristics of Epoxy Through Dispersion of Multi-walled Carbon Nanotubes in Supercritical Carbon Dioxide. Carbon Letters. vol. 14 no. 4, pp. 218-227.

27. B. Yu, Z. Jiang, X.-Z. Tang, Y. Y. Chee and J. Yang. (2014). Enhanced Interphase Between Epoxy Matrix and Carbon Fiber with Carbon Nanotube-Modified Silane Coating. Composites Science and Technology. vol. 99, pp. 131-140.

28. M. Wladyka-Przybylak, D. Wesolek, W. Gieparda, A. Boczkowska and E. Ciecierska. (2011). Functionalization Effect on Physico-mechanical Properties of Multi-walled Carbon Nanotubes/Epoxy Composites. Polymer Advanced Technologies. vol. 22, no. Research Article, pp. 48-59.

29. M. A. Rosli (2013). Wear Behavior of Carbon Nanotube (CNT)/Short Natural Fiber Reinforced Epoxy Composite. Universiti Teknikal Malaysia Melaka, Melaka.

30. W. Lei. (2005). Preparation, Morphology and Thermal/Mechanical Properties of Epoxy-Nanoclay Composites. National University of Singapore.

31. I. Juutilainen, J. Röning and L. Mylliykoski, "Modelling the Strength of Steel Plates Using Regression Analysis and Neural Networks," University of Oulu, Raahe.

32. S. Kalayci, "Multi Varied Statistical Techniques and SPSS Application," Asil, Ankara, 2006.

33. J. G. Mackinnon and R. Davidson, "Chapter 1 Regression Models," in Econometric Theory and Methods, OUP Oxford, 1999 2004, pp. 3-42.

34. B. F. Yousif, A. Shalwan, C. Chin and K. Ming. (2012). Flexural Properties of Treated and Untreated Kenaf/Epoxy Composites. Materials and Design. pp. 378-385.

35. T. Nishino, K. Hirao, M. Koreta, K. Nakamae and H. Inagaki. (2003). Kenaf Reinforced Biodegradable Composite. Composite Science and Technology. pp. 1281-1286.

36. M. R. Yusof Hamid, M. H. Ab Ghani and S. Ahmad. (2012). Effect of Antioxidants and Fire Retardants as Mineral Fillres on the Physical and Mechanical Properties of Hight Loading Hybrid Bicomposites Reinforced with Rice Husks and Sawdust. Industrial Crops and Products. vol. 40, pp. 96-102.

\section{AUTHORS PROFILE}

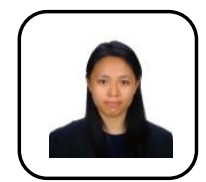

Chai Hua, T. is a postgraduate from Faculty of Engineering, Universiti Putra Malaysia. Her area of expertise is in nanotechnology. To date, she has published 2 articles in journals

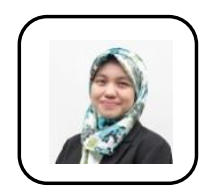

Norkhairunnisa, $\mathbf{M}$ is a senior lecturer from Faculty of Engineering, Universiti Putra Malaysia, majoring in nanotechnology. To date, she has published more than 50 articles in numerous journals, book chapters, proceeding etc. 